\title{
Experimental evidence of inbreeding avoidance in the hermaphroditic snail Physa acuta
}

\author{
Benoît Facon · Virginie Ravigné · Jérôme Goudet
}

Received: 3 November 2005 / Accepted: 17 February 2006

(C) Springer Science+Business Media B.V. 2006

\begin{abstract}
Inbreeding depression should select for inbreeding avoidance behaviours. Here we test this hypothesis in two populations of the simultaneous hermaphroditic freshwater snail Physa acuta. We recorded the copulatory behaviour of 288 pairs of sib-mates, nonkin mates from the same population, or non-kin mates from two different populations. We find that kin discriminatory behaviours exist in this species, exclusively expressed by individuals playing the female role. We discuss the relevance of our finding in the context of the evolution of recognition systems and the consequences of such a behaviour in natural populations.
\end{abstract}

Keywords Mating behavior - Inbreeding avoidance $\cdot$ Mate choice $\cdot$ Freshwater snail $\cdot$ Hermaphroditic $\cdot$ Intersexual conflict

\section{Introduction}

Spatial and temporal landscape heterogeneity may cause populations to undergo small effective size or punctual bottlenecks. By restricting opportunities for mating, small populations foster inbreeding via mating among relatives. Such crosses often result in depressed fitness progeny, a phenomenon referred to as inbreeding depression (Keller and Waller 2002; Glémin et al. 2003). In species suffering from inbreeding depression, selection should theoretically favour the emergence of mechanisms to avoid crosses between closely related

B. Facon $(\bowtie) \cdot$ V. Ravigné $\cdot$ J. Goudet

Department of Ecology and Evolution, University of Lausanne, Biology Building, Dorigny 1015,

Switzerland

e-mail: benoit.facon@unil.ch

V. Ravigné

UMR ECOBIOP, INRA, Quartier Ibarron, 64310, Saint Pée sur Nivelle, France 
individuals (Pusey and Wolf 1996; Meagher et al. 2000; Kruuk et al. 2002; Tregenza and Wedell 2002). In animals, these include sex-specific dispersal (Perrin and Mazalov 1999; Lehmann and Perrin 2003) and kin-discriminatory mate choice (Pusey and Wolf 1996; Reinhold 2002).

Mate choice entails either pre-copulatory partner choice behaviours (Blouin and Blouin 1988; Simmons 1991), or post-copulatory mechanisms. The latter may for instance rely on a female mating multiply to avoid having all its eggs fertilised by a poor sperm donor (i.e. dilution effect; Pizzari et al. 2004) as well as female cryptic sperm selection (Bishop 1996; Birkhead and Pizzari 2002). Furthermore as males are thought to have a higher reproductive potential than females (Bateman 1948; Trivers 1972), inter-sexual conflicts may exist over inbreeding avoidance behaviours (Smith 1979; Parker 1983; Perrin and Mazalov 2000), females being expected to be choosier than males. Congruently, in some species where males have a high investment in sperm production (e.g. nuptial gift), males should be as choosy as females (e.g. Lewis et al. 2004).

Both inbreeding avoidance and sex-specific inbreeding avoidance have been reported from numerous species with separate sexes (e.g. Pizzari et al. 2004, see Pusey and Wolf 1996 for a review). Inbreeding avoidance is also known from hermaphroditic plants in the form of incompatibility loci (e.g. Charlesworth and Awadalla 1998; Glémin et al. 2001). In simultaneous hermaphroditic animals, where sex-biased dispersal is impossible, inbreeding avoidance can only rely on mate choice.

Reproductive structures of hermaphroditic animals often show amazing complexity, and mating behaviour can be elaborate (Michiels 1998; Schilthuizen 2005). Prolonged courtship gives ample opportunity for partner assessment, which may set the stage for mate choice. Several studies have been carried out in hermaphroditic animals to test mate choice with respect to different parameters such as body size (e.g. Vreys and Michiels 1997; OhbayashiHodoki et al. 2004; Jordaens et al. 2005) or geographic origin (Baur and Baur 1992). However, studies investigating the consequences of relatedness on sex-specific mate choice in hermaphroditic animals are still scarce (but see Peters and Michiels 1996; Baur and Baur 1997). One possible reason is that many hermaphroditic species have simultaneous bilateral sperm transmission. In such cases, both individuals play symmetrical roles, and distinguishing between male-specific and female specific mate choice behaviours is difficult.

Physa acuta is a good candidate for investigating sex-specific inbreeding avoidance behaviours, as in this simultaneous hermaphroditic freshwater snail, individuals may be either male or female at each copulation (but not the two simultaneously). Sex-roles can thus easily be distinguished. Although self-fertilisation is possible, $P$. acuta is a preferential outcrosser with selfing rates generally lower than 0.1 in natural populations (Jarne et al. 2000; Bousset et al. 2004). Large self-fertilisation depression was detected both in laboratory conditions (up to 0.9 over a full life-cycle, Jarne et al. 2000) and in the field (Henry et al. 2003). The ecology of the species also implies that it is likely to undergo inbreeding through extremely small population sizes. It is an invasive species and European populations were recently founded presumably from a North American source (Dillon et al. 2002) through demographic and genetic bottlenecks. Moreover, the species often dwells in temporary habitats and thus goes through recurrent bottlenecks and/or extinctions (Städler and Jarne 1997). Even large populations may show drastic variations in effective size. Critical ingredients are thus gathered for Physa acuta to exhibit kin discrimination in its mate choices.

Here we test whether $P$. acuta exhibits inbreeding avoidance behaviours both at the scale of one population (kin vs. sympatric) and at the scale of two populations (kin vs. allopatric). We find that inbreeding avoidance behaviours exist in this species and are mainly due to kin rejection expressed when playing the female role.

空 Springer 


\section{Material and methods}

\section{Populations studied}

Two populations were studied and, respectively sampled at Vidy (VID; 46 $31^{\prime} \mathrm{N}, 6^{\circ} 36^{\prime}$ E) and Ecublens (ECU; 46 $31^{\prime}$ N, $6^{\circ} 32^{\prime}$ E) near Lausanne (Switzerland). These populations differ with respect to environmental conditions. Standing in a harbor of lake Léman, VID exhibits a permanent water regime and temperatures are relatively stable. On the contrary, ECU is a small irrigation canal often dry in summer and very cold in winter. Although densities can drastically vary in both populations (B. Facon, pers. obs.), the carrying capacity and effective size are doubtlessly higher in VID than in ECU. The dynamics of inbreeding depression, the intensity and efficiency of selection may thus differ between these two populations. They will therefore be treated separately in the analysis.

\section{Rearing protocol}

Throughout the experiment, snails were maintained at $24^{\circ} \mathrm{C}$ under a $12 \mathrm{~L}: 12 \mathrm{D}$ photoperiod and fed ad libitum with boiled lettuce. Mature individuals $\left(G_{0}\right)$ were sampled in each population (in December 2004), brought back to the laboratory, and isolated in $75 \mathrm{ml}$ plastic boxes filled with water. As body size and age may influence the mating behaviour of $P$. acuta (Ohbayashi-Hodoki et al. 2004), $G_{1}$ offspring similar with respect to size and age were obtained by collecting clutches only during the first 2 days in the lab. This restricted the experiment to 15 families of $16 G_{1}$ offspring for ECU and 16 families of $16 G_{1}$ offspring for VID. If reared in isolation, these snails take longer to reach sexual maturity (Tsitrone et al. 2003) and are craving so much for allosperm than they are not expected to show any discrimination concerning their partner's identity on the first encounter (Facon pers. obs.). $G_{1}$ juveniles from different families were thus mixed in boxes of 20 individuals, as soon as they were large enough $(>2 \mathrm{~mm})$ to be marked with gouache paint previously shown to be harmless (Henry et al. 2003). Groups were carefully composed so as to avoid any bias due to relatedness in their breeding environment. This treatment lasted until all snails were sexually mature. It thus allowed individuals to mate freely (around 50 days after clutches were produced; see MonsuttiGrecescu 1998). Individuals were then isolated during 10 days. This ensures that all tested individuals will seek for new copulations during the pair tests (Wethington and Dillon 1996).

\section{Pair tests}

We recorded the mating behaviour of individuals from 12 families in each population when they were presented to partners of different levels of relatedness. Figure 1 shows the experimental design used for the population VID, the same design was used for ECU. Twelve focal $G_{1}$ individuals per family were tested. Four were presented to a partner sampled among the 12 families of the other population. Pairs were carefully chosen to avoid any association between families from the two populations. Four were presented to a non-kin partner of the same population sampled among the three remaining families not serving as tested families for ECU and the four remaining families for VID. The last four $G_{1}$ individuals of each family were presented to a sib. Once formed, each pair was observed during one full hour. All observations were obtained within a 3-days period. 


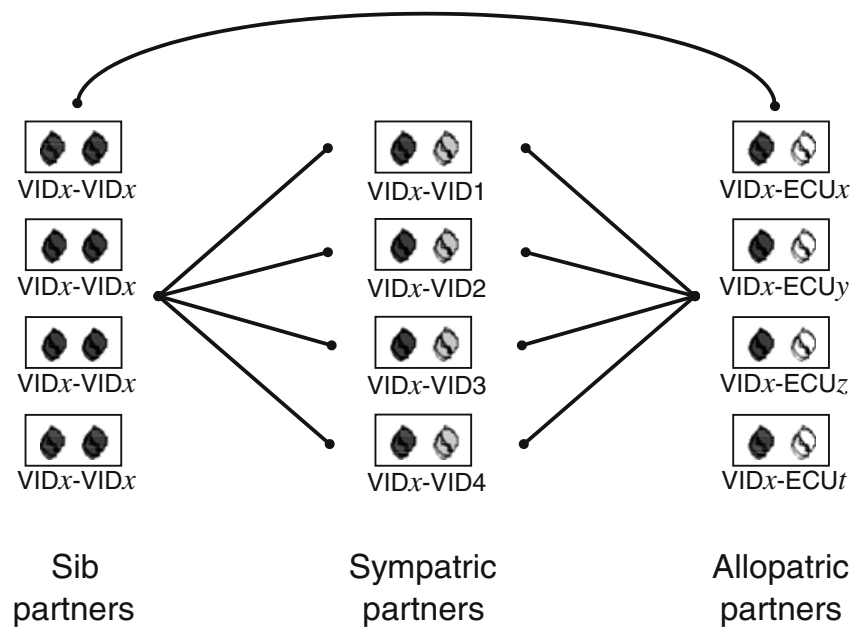

Fig. 1 Pairs tested for their reproductive behaviour in each family. The design is given for a VID family but is similar for an ECU. Twelve individuals of the tested family VID $x$ are divided into three groups of four. Individuals of the first group receive a sib partner. Individuals of the second group are confronted to a partner of the same population (one of the four VID families used as sources of such partners). Individuals of the third group receive a partner randomly drawn in a family of the other population ECU. Lines show the pair comparisons used for the statistical analysis, which results are shown in Tables 1 and 2

A typical copulation involves (i) approach and climbing onto the shell of an intended female by a male role snail, (ii) crawling to the female gonophore, (iii) preputium eversion for intromission (copulations may last up to $15 \mathrm{~min}$ ), and (iv) dismounting (OhbayashiHodoki et al. 2004). Male rejection behaviours, if they exist (as suggested by McCarthy 2004) would take the form of mounting avoidance and early dismounting. Female rejection behaviours may express through shell swinging and phallus biting. During the $1 \mathrm{~h}$ observation, we recorded the time to each contact, copulation and dismounting. For each copulation, we also recorded individual gender role and occurrence of rejection behaviour. The following variables were analysed: time to first copulation $\left(T_{1 s t}\right.$ cop $)$, total duration of all observed copulations (phase iii) during the observation period $\left(\mathrm{D}_{\mathrm{cop}}\right)$ and proportion of copulations where rejection occurred $\left(\mathrm{P}_{\mathrm{rej}}\right)$.

\section{Statistical analyses}

Statistical analyses were conducted using the software R ( $R$ development Core team 2004). For the three variables, averages of the four replicates per family were calculated for each mating type. Differences between kin and non-kin mating (Sib vs. Sympatric and Sib vs. Allopatric) were tested using an unilateral matched-pairs Wilcoxon test, with the expectation that non-kin partners copulate earlier $\left(\mathrm{T}_{1 \mathrm{st} \text { cop }}\right)$, have a longer copulation period $\left(\mathrm{D}_{\text {cop }}\right)$ and a lower rejection propensity $\left(\mathrm{P}_{\text {rej }}\right)$ than kin partners. Differences between sympatric and allopatric mating trials were tested using a bilateral matched-pairs Wilcoxon test, as we had no a priori expectations for these. In order to avoid pseudo-replication caused by the availability of only three ECU and four VID families of sympatric partners, differences involving sympatric pairs were tested separately for each sympatric family (Fig. 1). Differences between the two populations were checked using a bilateral Wilcoxon test on the sib and sympatric mating only, as allopatric crosses of each population are not independent. 


\section{Results}

Within the $1 \mathrm{~h}$ observation period, $94.7 \%$ of the pairs copulated at least once. The number of copulations observed in $1 \mathrm{~h}$ ranged from 0 to 7 for a mean number of copulations of 2.58 and a mean copulation time of $308.0 \mathrm{~s}$. Figures 2 and 3 show the mean family reaction norms for VID and ECU, respectively. Mean values of the traits over all families as well as $P$-values are given in Tables 1 and 2 .

Fig. 2 Effect of relatedness on mating behaviour in the population VID. (a) Time of first copulation $\left(\mathrm{T}_{1 \text { stcop }}\right)$. (b) Total duration of copulation $\left(\mathrm{D}_{\mathrm{cop}}\right)$. (c) Proportion of copulations with rejections $\left(\mathrm{P}_{\mathrm{rej}}\right)$. For the sympatric treatment, mean behaviours were shown separately for each partner family (square: VID1; circle: VID2; triangle: VID3; cross: VID4). Standard errors and statistical significance of the paired tests are given in Table 1. The mean number of copulations was 2.60 for sib pairs, 2.79, 2.82, 4.09, 2.33 , respectively, for sympatric pairs involving VID1, VID 2, VID3 and VID4, and 2.85 for allopatric pairs
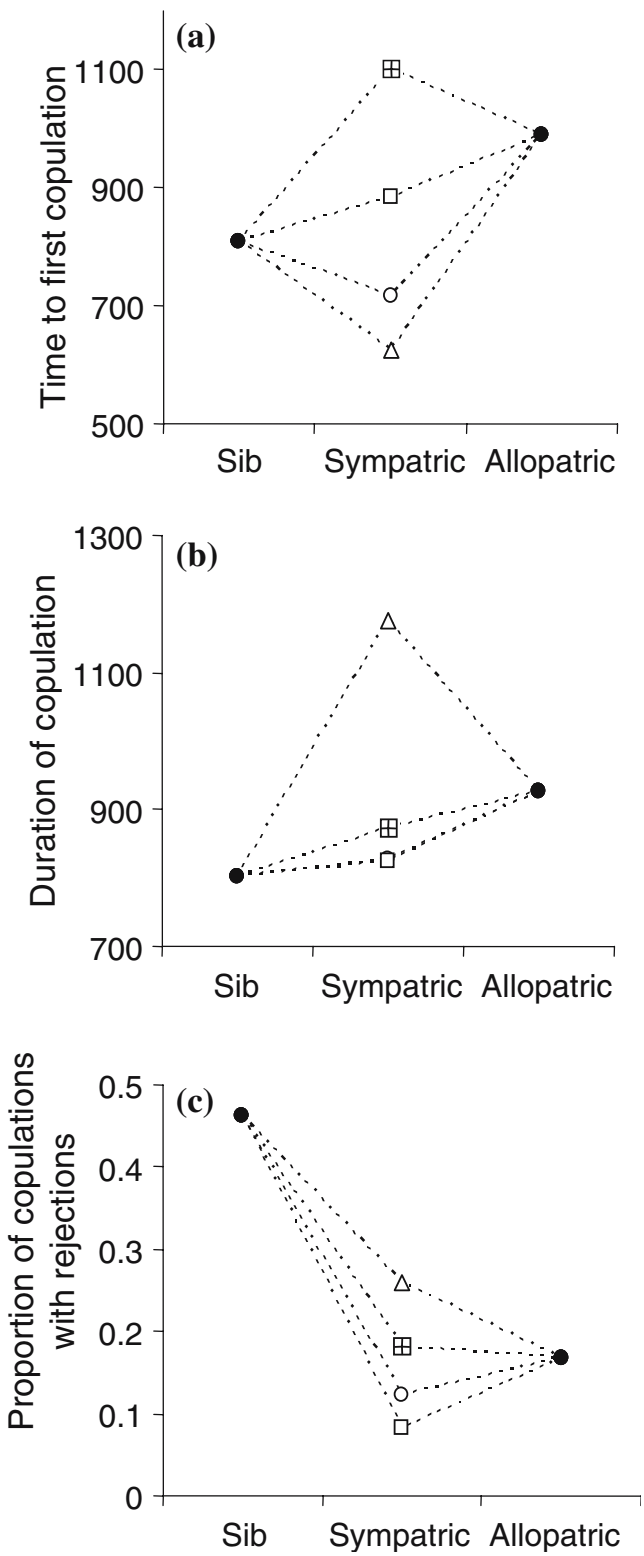

글 Springer 
VID population

The time to first copulation was not significantly different between the three treatments except between allopatric mating and the sympatric line VID3 (Table 1 and Fig. 2a).

Kin partners tended to mate for shorter time than non-kin but this trend was significant only for allopatric partners and for the sympatric family VID3 (Table 1 and Fig. 2b).

Fig. 3 Effect of relatedness on mating behaviour in the population ECU. (a) Time of first copulation $\left(\mathrm{T}_{1 \text { stcop }}\right)$. (b) Total duration of copulation $\left(\mathrm{D}_{\mathrm{cop}}\right)$. (c) Proportion of copulations with rejections $\left(\mathrm{P}_{\mathrm{rej}}\right)$. For the sympatric treatment, mean behaviours were shown separately for each partner family (cross: ECU1; circle: ECU2; triangle: ECU3). Standard errors and statistical significance of the paired tests are given in Table 2 . The mean number of copulations was 1.96 for sib pairs, 2.37, 2.17, 2.07 , respectively, for sympatric pairs involving ECU1, ECU2 and ECU3 and 2.85 for allopatric pairs
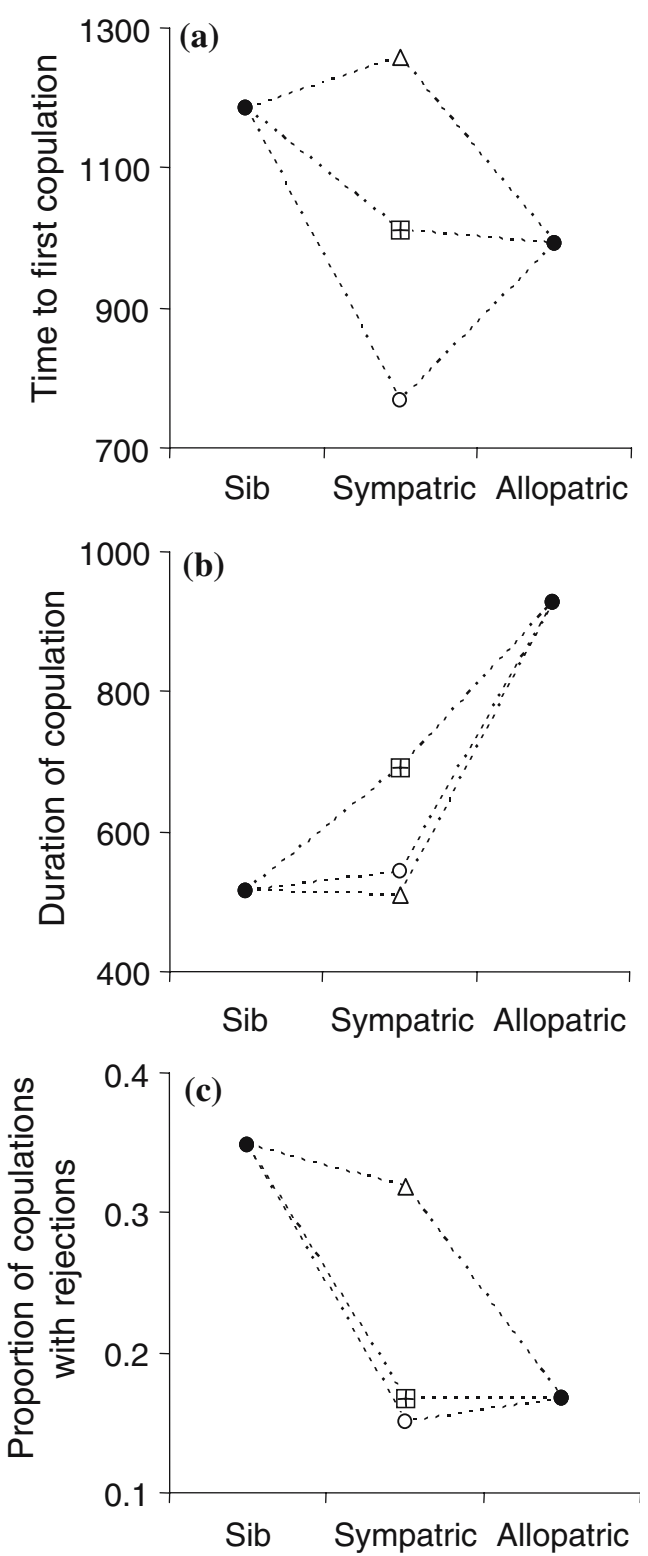
Table 1 Mean values of the three traits for each kind of cross and results of the Wilcoxon tests for the VID population

\begin{tabular}{|c|c|c|c|c|c|}
\hline & Kin & $P$-value & $\begin{array}{l}\text { VID1 } \\
\text { VID2 } \\
\text { VID3 } \\
\text { VID4 }\end{array}$ & $P$-value & Allopatric \\
\hline $\mathrm{T}_{1 \text { stcop }}$ & $808.37 \pm 100.97$ & $\begin{array}{l}0.58 \\
0.16 \\
0.14 \\
0.90\end{array}$ & $\begin{array}{l}885.5 \pm 149.70 \\
715.56 \pm 170.33 \\
624.75 \pm 99.10 \\
1100.0 \pm 212.34\end{array}$ & $\begin{array}{l}0.38 \\
\mathbf{0 . 1 0} \\
\mathbf{0 . 0 1} \\
0.52\end{array}$ & $\begin{array}{l}990.24 \pm 128.07 \\
P=0.95\end{array}$ \\
\hline$D_{\text {cop }}$ & $801.88 \pm 72.38$ & $\begin{array}{l}0.71 \\
0.62 \\
\mathbf{0 . 0 5} \\
0.48\end{array}$ & $\begin{array}{l}824.09 \pm 215.72 \\
828.25 \pm 199.16 \\
1176.0 \pm 159.45 \\
871.82 \pm 207.30\end{array}$ & $\begin{array}{l}0.70 \\
0.56 \\
0.19 \\
0.32\end{array}$ & $\begin{array}{l}927.25 \pm 73.60 \\
P=\mathbf{0 . 0 5}\end{array}$ \\
\hline$P_{\text {rej }}$ & $0.46 \pm 0.10$ & $\begin{array}{l}\text { 0.02 } \\
0.05 \\
\text { 0.08 } \\
\text { 0.01 }\end{array}$ & $\begin{array}{l}0.08 \pm 0.04 \\
0.12 \pm 0.08 \\
0.26 \pm 0.07 \\
0.18 \pm 0.08\end{array}$ & $\begin{array}{l}0.32 \\
0.33 \\
0.56 \\
1\end{array}$ & $\begin{array}{l}0.17 \pm 0.03 \\
\boldsymbol{P}=\mathbf{0 . 0 2}\end{array}$ \\
\hline
\end{tabular}

The left (right) " $P$-value" column contains $P$-values of Wilcoxon tests between sib (allopatric) mating and sympatric mating with each sympatric family. The $P$-Value in the "Allopatric" column corresponds to differences between sib and allopatric mating

Table 2 Mean values of the three traits for each kind of cross and results of the Wilcoxon tests for the ECU population

\begin{tabular}{llllll}
\hline & Kin & $P$-value & $\begin{array}{l}\text { ECU1 } \\
\text { ECU2 } \\
\text { ECU3 }\end{array}$ & $P$-value & Allopatric \\
& & & & \\
\hline $\mathrm{T}_{1 \text { stcop }}$ & \multirow{2}{*}{$1185.83 \pm 132.71$} & 0.19 & $1010.25 \pm 175.17$ & 0.85 & $990.24 \pm 128.07$ \\
& & 0.62 & $1257.05 \pm 180.65$ & 0.37 & $P=0.17$ \\
$\mathrm{D}_{\text {cop }}$ & $514.15 \pm 63.30$ & 0.16 & $692.27 \pm 187.06$ & 0.24 & $927.25 \pm 78.02$ \\
& & 0.55 & $507.95 \pm 87.27$ & $\mathbf{0 . 0 1}$ & $\boldsymbol{P}=\mathbf{0 . 0 0 1}$ \\
$\mathrm{P}_{\text {rej }}$ & $0.35 \pm 0.09$ & 0.54 & $543.25 \pm 71.86$ & $\mathbf{0 . 0 2}$ & \\
& & $\mathbf{0 . 0 6}$ & $0.17 \pm 0.07$ & 0.92 & $0.17 \pm 0.04$ \\
& & 0.27 & $0.32 \pm 0.10$ & 0.19 & $\boldsymbol{P}=\mathbf{0 . 0 5}$ \\
& & $\mathbf{0 . 0 3}$ & $0.15 \pm 0.04$ & 0.72 &
\end{tabular}

The left (right) " $P$-value" column contains $P$-values of Wilcoxon tests between sib (allopatric) mating and sympatric mating with each sympatric family. The $P$-value in the "Allopatric" column corresponds to differences between sib and allopatric mating

Rejections were more frequent between kin partners than between allopatric partners and between sympatric partners (Table 1 and Fig. 2c). There were no significant differences in the proportions of rejections between sympatric and allopatric partners.

\section{ECU population}

The time to first copulation did not significantly differ between the three types of mating except between sib mating and the sympatric family ECU3 (Table 2 and Fig. 3a).

Kin partners tended to mate for a shorter time than non-kin but this trend was significant only for allopatric partners. Allopatric partners also mated significantly longer than sympatric partners for two sympatric families (Table 2 and Fig. 3b). 
The type of mating strongly affected the proportion of copulations with rejections inflicted by female-role snails (Table 2 and Fig. 3c). Rejections were more frequent between kin partners than between allopatric partners and between sympatric partners for two sympatric families. There were no significant differences of proportion of rejections between sympatric and allopatric partners.

\section{Comparisons between populations}

There was no difference between the two populations with regards to rejection propensities $\left(\mathrm{P}_{\text {rej }}\right)$. When given a kin partner, VID copulated earlier $\left(\mathrm{T}_{1 \text { stcop }}, P=0.05\right)$ and had a longer copulation period $\left(\mathrm{D}_{\text {cop }}, P=0.005\right)$ than ECU. When given a sympatric partner, VID also copulated earlier $\left(\mathrm{T}_{1 \text { stcop }}, P=0.09\right)$ and had a longer copulation period $\left(\mathrm{D}_{\text {cop }}, P=0.02\right)$ than ECU. Noticeably in both populations, the consequences of relatedness on mating behaviour differed according to the family considered.

\section{Discussion}

Evidence of inbreeding avoidance behaviours

Our results reveal the existence of kin discriminatory mate choice behaviours in Physa acuta. The higher the partners relatedness, the more frequent the rejection attempts. These rejections take the form of shell swinging and phallus biting inflicted by female role snails to their partner. It has been suggested that rejections by male acting snails also exist, for instance through mounting avoidance and/or interrupted copulations (McCarthy 2004). When two individuals separate without obvious female rejection, it is difficult to attribute the separation to a male rejection with certainty. The effect of male rejection may, however, be measured through an increased time to first contact, an increased time to first copulation and shortened copulations. We found no evidence of a difference in the time to first contact (result not shown) or the time to first copulation between kin and non-kin pairs, suggesting that male acting snails do not avoid copulation with kin partners. Copulation duration tended to be shorter for kin than non-kin pairs, the trend being only clearly significant in population ECU. But this pattern could stem from a higher female rejections rate. Therefore discrimination as male if it exists seems not as strong as discrimination as female. This corroborates the hypothesis that male function is cheaper than the female in this species.

This finding raises the question of how recognition is achieved. Freshwater snails can perceive chemical signals in the water and on the ground. In particular, growth (Kawata and Ishigami 1992), fecundity (Levy et al. 1973) and motion (Karowe et al. 1993) differ in presence of conspecific signals as compared to signals from other species. In the snail Biomphalaria glabrata, mate choice based on partner infection status was suggested to involve the recognition of chemical compounds in the snail's mucous or shell composition, comparable to the vertebrate MHC, which may be detected during the mutual allo-grazing periods that precede copulation (Webster et al. 2003). Here we find that neither the time to first contact nor the time to first copulation are affected by partner relatedness. As snails are relatively mobile, this suggests that recognition is not mediated by chemical compounds dissolved in the water but rather occurs at penis intromission or later trough contact signals (e.g. as in rotifers, Snell and Morris 1993). 
In our experiment, greater rejection rates were associated with shorter copulations as expected. More surprising is that this trend was only clearly significant for comparisons with allopatric partners. One can then wonder whether rejections are an efficient mean to end up an unwilled copulation in the wild. Beyond a potential lack of statistical power for comparisons implying sympatric partners, one can imagine that the "no choice" design gives an advantage to males in the inter-sexual conflict over mate choice. In this experimental design, only one male is available and the female is confronted several times to the same partner. The efficiency of rejections is thus reduced. In nature on the contrary, individuals might have fewer opportunities to meet again after an aborted copulation. That a female successfully rejects a male gives her access to other males with different relatedness. Rejections could thus prove more efficient at shortening unwilled copulations in nature than suggested by our experiment.

Genetic load has been shown to vary among families (Jarne et al. 2000; Henry et al. 2003). If fully adaptive, inbreeding avoidance should depend on the number of deleterious mutations carried in a family, i.e. the family genetic load. Avoiding mating with kin is only adaptive in families with a high genetic load. Then mating choices should differ between families. Although the present design does not allow testing for such differences, inbreeding avoidance behaviours show some variation among families. For instance, some families seem to reject kin partners less than others. Family differences could be due to either genetic or early environmental processes. Checking whether inbreeding avoidance is conditional on family genetic load requires further investigation. In particular, a simultaneous assessment of family mate choice behaviour and inbreeding depression is clearly needed.

\section{Implications for natural populations}

Whether the pre-copulatory behaviours of inbreeding avoidance highlighted here are a major determinant of mating patterns in natural populations needs to be further investigated. Wethington and Dillon (1993) have detected incompatibility between gametes of the same individual and to a lesser extent between gametes of different individuals. This suggests that the mechanistic basis for female cryptic sperm selection exist, although conclusive evidence is still lacking. Post-copulatory mate choice may thus reinforce inbreeding avoidance in this species. If cryptic sperm selection is possible, conflicts should be less intense when several partners are available as compared to a one-to-one situation. When several partners are available, low quality copulations may have little consequences on fecundity and offspring performance. In one-to-one interactions, conflicts should intensify, both individuals willing to be a male in presence of a sib (Angeloni et al. 2002). The relative importance of pre- and post-copulatory mate choice could thus well differ according to partner availability in the wild.

The existence of kin discriminatory mate choice was expected in this species. First it suffers from high levels of inbreeding depression (Jarne et al. 2000), possibly linked to the recurrent bottlenecks that may have accompanied its recent colonisation of Europe (Dillon et al. 2002). Second, P. acuta exhibits delayed selfing, that can be seen as a form of inbreeding avoidance (Tsitrone et al. 2003). Inbreeding depression is thus high enough in this species for some inbreeding avoidance to evolve. Restricting inbreeding avoidance to self-fertilisation avoidance would only be adaptive in well-mixed and large populations where the probability to mate with a kin is low. Congruently with this idea, it seems that ECU, the small population, exhibits greater choosiness that VID, the large lake population. 
More surprising is the existence of behaviours favouring mating with allopatric over sympatric partners. In population ECU, snails also mate longer and make less rejection attempts when interacting with an allopatric partner than with a sympatric partner. These behaviours may simply exist as a by-product of the evolution of a kin-discrimination system selected at a local scale. Alternatively they may be selected directly. That ECU exhibits greater preference for VID individuals than the reverse is consistent with the selection hypothesis: small populations are more subject to drift and random fixation of deleterious mutations. The benefit of heterosis through allopatric mating might thus be greater for ECU than VID.

For the two populations considered here, no evidence of outbreeding avoidance was found at the scale considered here. This differs from a previous experiment where greater avoidance rates were found in allopatric pairs as compared to sympatric ones using two American populations of Physa acuta (called P. gyrina in the original paper, McCarthy 2004). P. acuta has a world-wide distribution and occupies a great variety of habitats (temporary or permanent ponds, lakes, rivers...). In Europe, population differentiation at neutral loci has been documented at several scales (Bousset et al. 2004), and the same is likely true for loci and traits under selection. If local adaptation occurs, outbreeding depression and thus outbreeding avoidance should be found at some scale. Since interfertility between P. acuta and two other Physa species has recently been documented (Dillon et al. 2002), the scale at which outbreeding depression could occur is huge. Fitness estimates of crosses of increasing partner distance, ranging from self-fertilisation to interspecific cross, could allow determining the optimal distance of crosses in this species. This large scale makes $P$. acuta an ideal animal model for investigating the relative importance of genetic load and local adaptation in natural populations.

Acknowledgements VR and BF each benefited from a Lavoisier post-doctoral grant from the Ministère Français des Affaires Etrangères. VR was hosted by group Keller at the University of Lausanne. This study was supported by grant 31-108194/1 from the Swiss National Foundation. We are grateful to E. Chapuis, J. Cosendai, L. Gigord and P. Gigord for their help in snails rearing. We also thank G. Bernasconi,

G. Evanno and L. Keller who all provided helpful comments on the manuscript.

\section{References}

Angeloni L, Bradbury JW, Charnov EL (2002) Body size and sex allocation in simultaneously hermaphroditic animals. Behav Ecol 13:419-426

Bateman AJ (1948) Intra-sexual selection in Drosophila. Heredity 2:349-368

Baur B, Baur A (1992) Reduced reproductive compatibility in Arianta arbusotrum (Gastropoda) from distant populations. Heredity 69:65-72

Baur B, Baur A (1997) Random mating with respect to relatedness in the simultaneously hermaphrodite land snail Arianta arbustorum. Invertebr Biol 116:294-298

Birkhead TR, Pizzari T (2002) Postcopulatory sexual selection. Nat Rev Genet 3:262-273

Bishop JD (1996) Female control of paternity in the internally fertilizing compound ascidian Diplosoma listerianum. 1. Autoradiographic investigation of sperm movements in the female reproductive tract. Proc R Soc Lond B 263:369-376

Blouin SF, Blouin M (1988) Inbreeding avoidance behaviours. Trends Ecol Evol 3:230-233

Bousset L, Henry P.-Y, Sourrouille P, Jarne P (2004) Population biology of the invasive freshwater snail Physa acuta approached through genetic markers, ecological characterization and demography. Mol Ecol 13:2023-2036

Charlesworth D, Awadalla P (1998) Flowering plant self-incompatibility, the molecular population genetics of Brassica S-loci. Heredity 81:1-9 
Dillon RT, Wethington AR, Rhett JM, Smith TP (2002) Populations of the European freshwater pulmonate Physa acuta are not reproductively isolated from American Physa heterostropha or Physa integra. Invertebr Biol 121:226-234

Glémin S, Bataillon T, Ronfort J, Mignot A, Olivieri I (2001) Inbreeding depression in small populations of self-incompatible plants. Genetics 159:1217-1229

Glémin S, Ronfort J., Bataillon T (2003) Patterns of inbreeding depression and architecture of the load in subdivided populations. Genetics 165:2193-2212

Henry P.-Y, Pradel R, Jarne P (2003) Environment-dependent inbreeding depression in a hermaphroditic freshwater snail. J Evol Biol 16:1211-1222

Jarne P, Perdieu M.-A, Pernot A.-F, Delay B, David P (2000) The influence of self-fertilization and grouping on fitness attributes in the freshwater snail Physa acuta: population and individual inbreeding depression. J Evol Biol 13:645-655

Jordaens K, Pincel J, Backeljau T (2005) Mate choice in the hermaphroditic land snail Succinea putris (Stylommatophora: Succineidae). Anim Behav 70:329-337

Karowe DN, Pearce TA, Spaller WR (1993) Chemical communication in freshwater snails: behavioural responses of Physa parkeri to mucous trails of $P$. parkeri (Gastropoda: Pulmonata) and Campeloma decisum (Gastropoda: Prosobranchia). Malacol Rev 26:9-14

Kawata M, Ishigami H (1992) The growth of juvenile sails in water conditioned by snails of a different species. Oecologia 91:245-248

Keller LF, Waller DM (2002) Inbreeding effects in wild populations. Trends Ecol Evol 17:230-241

Kruuk LEB, Sheldon BC, Merila J (2002) Severe inbreeding depression in collared flycatchers (Ficedula albicollis). Proc R Soc Lond B 269:1581-1589

Lehmann L, Perrin N (2003) Inbreeding avoidance through kin recognition, Choosy females boost male dispersal. Am Nat 162:638-652

Levy MG, Tunis M, Sseroff H (1973) Population-control in snails by natural inhibitors. Nature 241:65-66

Lewis SM, Cratsley CK, Rooney JA (2004) Nuptial gifts and sexual selection in Photinus Fireflies. Integr Comp Biol 44:234-237

McCarthy T (2004) Effects of pair-type and isolation time on mating interactions of a freshwater snail, Physa gyrina (Say, 1821). Am Malacol Bull 19:1-9

Meagher S, Penn DJ, Potts PW (2000) Male-male competition magnifies inbreeding depression in wild house mice. Proc Natl Acad Sci USA 97:3324-3329

Michiels NK (1998) Mating conflicts and sperm competition in simultaneous hermaphrodites In: Birkhead TR, Møller AP (eds) Sperm competition and sexual selection. Academic Press London, pp 219-254

Monsutti-Grecescu A (1998) Prédation taille-dépendante et paramètres du cycle vital chez Physa acuta (Gastropoda). PhD Thesis, University of Lausanne, Lausanne, Switzerland

Ohbayashi-Hodoki K, Ishihama F, Shimada M (2004) Body size-dependent gender role in a simultaneous hermaphrodite freshwater snail, Physa acuta. Behav Ecol 15:976-981

Parker GA (1983) Mate quality and mating decisions. In: Bateson P (ed) Mate choice. Cambridge University Press, pp 141-164

Perrin N, Mazalov V (1999) Dispersal and inbreeding avoidance. Am Nat 154:282-292

Perrin N, Mazalov V (2000) Local competition, inbreeding, and the evolution of sex-biased dispersal. Am Nat 155:116-127

Peters A, Michiels NK (1996) Evidence for lack of inbreeding avoidance by selective mating in a simultaneous hermaphrodite. Invertebr Biol 115:99-103

Pizzari T, Løvlie H, Cornwallis CK (2004) Sex-specific, counteracting responses to inbreeding in a bird. Proc R Soc Lond B 271:2115-2121

Pusey A, Wolf M (1996) Inbreeding avoidance in animals. Trends Ecol Evol 11:201-206

$\mathrm{R}$ development Core team (2004) R: a language and environment for statistical computing. R Foundation for Statistical Computing, Vienna, Austria. URL: http://www.R-project.org. ISBN: 3-900051-00-3

Reinhold K (2002) Modeling the evolution of female choice strategies under inbreeding conditions. Genetica 116:189-195

Schilthuizen M (2005) The darting game in snails and slugs. Trends Ecol Evol (in press)

Simmons LW (1991) Female choice and the relatedness of mates in the field cricket, Gryllus bimaculatus. Anim Behav 41:493-501

Smith RH (1979) On selection for inbreeding in polygynous animals. Heredity 43:205-211

Snell TW, Morris PD (1993) Sexual communication in copepods and rotifers. Hydrobiologia 255:109-116

Städler T, Jarne P (1997) Population biology, genetic structure and mating system parameters in freshwater snails In: Streit B, Städler T, Lively CM (eds) Ecology and evolution of freshwater organisms. Birkhäuser Verlag Basel pp 231-262 
Tregenza T, Wedell N (2002) Genetic compatibility, mate choice and patterns of parentage. Mol Ecol 9:1013-1027

Trivers RL (1972) Parental investment and sexual selection In: Campbell B (ed) Sexual selection and the descent of man. Aldine-Atherton Chicago pp 136-179

Tsitrone A, Jarne P, David P (2003) Delayed selfing and resource reallocations in relation to mate availability in the freshwater snail Physa acuta. Am Nat 162:474-488

Vreys C, Michiels NK (1997) Flatworms flatten to size up each other. Proc R Soc Lond B 264:1559-1564

Webster JP, Hoffman JI, Berdoy M (2003) Parasite infection, host resistance and mate choice: battle of the genders in a simultaneous hermaphrodite. Proc R Soc Lond B 270:1481-1485

Wethington AR, Dillon RT (1993) Reproductive development in the hermaphroditic fresh-water snail Physa monitored with complementing albino lines. Proc R Soc Lond B 252:109-114

Wethington AR, Dillon RT (1996) Gender choice and gender conflict in a non-reciprocally mating simultaneous hermaphrodite, the freshwater snail, Physa. Anim Behav 51:1107-1118 